\title{
In favour of the definition "adolescents with idiopathic scoliosis": juvenile and adolescent idiopathic scoliosis braced after ten years of age, do not show different end results
}

\author{
Sabrina Donzelli ${ }^{1 *}$, Monia Lusini ${ }^{1}$, Salvatore Minnella', Fabio Zaina ${ }^{1}$, Stefano Negrini ${ }^{2}$ \\ From 11th International Conference on Conservative Management of Spinal Deformities - SOSORT 2014 \\ Annual Meeting \\ Wiesbaden, Germany. 8-10 May 2014
}

\section{Background}

The most important factor discriminating juvenile (JIS) from adolescent idiopathic scoliosis (AIS) is the risk of deformity progression. Brace treatment can change natural history, even when risk of progression is high.

\section{Aim}

The aim of this study was to compare the end of growth results of JIS subjects, treated after 10 years of age, with final results of AIS.

\section{Design}

Prospective observational controlled cohort study nested in a prospective database started in March 2003.

\section{Methods}

Setting: outpatient tertiary referral clinic specialized in conservative treatment of spinal deformities.

Participants: Inclusion criteria: idiopathic scoliosis; European Risser $0-2 ; 25^{\circ}$ to $45^{\circ} \mathrm{Cobb}$; age 10 years or more at start of treatment. Exclusion criteria were for both groups: secondary scoliosis and pathologies known to be possible causes of scoliosis, neurological, previous treatment for scoliosis (brace or surgery).

\section{Groups}

29 patients ( 26 females, $32.24 \pm 6.34 \mathrm{Cobb}$ ) met the inclusion criteria for AJIS, (JIS treated in adolescence), according to an $\mathrm{x}$-ray before age 10 . AIS group included

${ }^{1}$ ISICO - Italian Scientific Spine Institute, Milan, Italy

Full list of author information is available at the end of the article
45 adolescents ( 37 females, $32.60 \pm 6.14^{\circ} \mathrm{Cobb}$ ) with a diagnostic $x$-ray made after the threshold of age 10. In both groups results at the end of growth were analysed; the threshold of $5^{\circ} \mathrm{Cobb}$ to define worsened, improved and stabilized curves was considered. Statistical analyses: Mean and SD were used for descriptive statistics of clinical and radiographic changes. Relative Risk of progression (RR), 95\% Confidence Interval (CI) of radiographic changes have been calculated.

\section{Results}

We did not find any Cobb angle significant differences among groups at baseline and at the end of treatment. In the AJIS group the percentage of worsened was $10.3 \%$ versus $6.67 \%$ in the AIS group.

The RR of progression of AJIS was 1.35 (IC95\% 0.573.17) versus AIS, and it wasn't statistically significant $(\mathrm{p}=0.5338)$.

\section{Conclusion}

Brace efficacy can neutralize the risk of progression. So the broad suggestion offered by these results is that there are no significant differences in the final results of AIS and JIS, treated with total respect of the SRS and SOSORT criteria, in adolescence. It is possible that JIS starting the treatment later, could be less aggressive than scoliosis that compel earlier treatment.

\section{Authors' details \\ ${ }^{1}$ ISICO - Italian Scientific Spine Institute, Milan, Italy. ${ }^{2}$ University of Brescia IRCCS Don Gnocchi, Brescia, Italy.}


doi:10.1186/1748-7161-9-S1-027

Cite this article as: Donzelli et al: In favour of the definition

"adolescents with idiopathic scoliosis": juvenile and adolescent

idiopathic scoliosis braced after ten years of age, do not show different end results. Scoliosis 2014 9(Suppl 1):O27.

Submit your next manuscript to BioMed Central and take full advantage of:

- Convenient online submission

- Thorough peer review

- No space constraints or color figure charges

- Immediate publication on acceptance

- Inclusion in PubMed, CAS, Scopus and Google Scholar

- Research which is freely available for redistribution

Submit your manuscript at 